\title{
Enhancing cutting tool sustainability based on remaining useful life prediction
}

Huibin Sun, Yang Liu, Junlin Pan, Jiduo Zhang and Wei Ji

The self-archived postprint version of this journal article is available at Linköping University Institutional Repository (DiVA):

http://urn.kb.se/resolve?urn=urn:nbn:se:liu:diva-163019

N.B.: When citing this work, cite the original publication.

Sun, H., Liu, Y., Pan, J., Zhang, J., Ji, W., (2020), Enhancing cutting tool sustainability based on remaining useful life prediction, Journal of Cleaner Production, 244, 118794.

https://doi.org/10.1016/j.jclepro.2019.118794

Original publication available at:

https://doi.org/10.1016/j.jclepro.2019.118794

Copyright: Elsevier

http://www.elsevier.com/

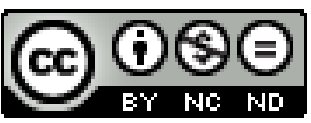




\section{Journal Pre-proof}

Enhancing cutting tool sustainability based on remaining useful life prediction

Huibin Sun, Yang Liu, Junlin Pan, Jiduo Zhang, Wei Ji

PII:

S0959-6526(19)33664-9

DOI:

https://doi.org/10.1016/j.jclepro.2019.118794

Reference:

JCLP 118794

To appear in:

Journal of Cleaner Production

Received Date:

08 June 2019

Accepted Date:

07 October 2019

Please cite this article as: Huibin Sun, Yang Liu, Junlin Pan, Jiduo Zhang, Wei Ji, Enhancing cutting tool sustainability based on remaining useful life prediction, Journal of Cleaner Production (2019), https://doi.org/10.1016/j.jclepro.2019.118794

This is a PDF file of an article that has undergone enhancements after acceptance, such as the addition of a cover page and metadata, and formatting for readability, but it is not yet the definitive version of record. This version will undergo additional copyediting, typesetting and review before it is published in its final form, but we are providing this version to give early visibility of the article. Please note that, during the production process, errors may be discovered which could affect the content, and all legal disclaimers that apply to the journal pertain.

(c) 2019 Published by Elsevier. 


\title{
Enhancing cutting tool sustainability based on remaining useful life prediction
}

\author{
Huibin Sun ${ }^{\text {a, *}}$, Yang Liu ${ }^{\text {b, c, * }}$, Junlin Pan a, Jiduo Zhang a, Wei Ji ${ }^{\mathrm{d}}$ \\ ${ }^{a}$ Laboratory of Contemporary Design and Integrated Manufacturing Technology, Ministry of \\ Education, Northwestern Polytechnical University, Xi'an, P. R. China
}

${ }^{\mathrm{b}}$ Department of Management and Engineering, Linköping University, SE-581 83 Linköping, Sweden

${ }^{c}$ Department of Production, University of Vaasa, 65200 Vaasa, Finland

d Department of Digital Machining, Sandvik Coromant, SE-126 79 Hägersten, Sweden

* Corresponding authors: sun_huibin@nwpu.edu.cn (H. Sun),yang.liu@liu.se (Y. Liu)

\begin{abstract}
As a critical part of machining, cutting tools are of great importance to sustainability enhancement. Normally, they are underused, resulting in huge waste. However, the lack of reliable support leads to a high risk on improving the cutting tool utilization. Aiming at this problem, this paper proposes an approach to enhance the cutting tool sustainability. A non-linear cutting tool remaining useful life prediction model is developed based on tool wear historical data. Probability distribution function and cumulative distribution function are used to quantize the uncertainty of the prediction. Under a constant machining condition, a cutting tool life is extended according to its specific remaining useful life prediction, rather than a unified one. Under various machining conditions, machining parameters are optimized to improve efficiency or capability. Cutting tool sustainability is assessed in economic, environmental and social dimensions. Experimental study verifies that both material removal rate and material removal volume are improved. Carbon emission and cutting tool cost are also reduced. The balance between benefit and risk is achieved by assigning a reasonable confidence level. Cutting tool sustainability can be enhanced by improving cutting tool utilization at controllable risk.
\end{abstract}

Keywords: cutting tool sustainability enhancement; remaining useful life prediction; cutting tool utilization improvement

\section{Introduction}

As a critical machining resource, cutting tools are of great importance to sustainability enhancement. Although cutting tool cost is less than $4 \%$ of machining cost (Astakhov, 2019), their abnormal states account for $10 \sim 40 \%$ of the total downtime of machine tools, and indirectly affected up to $30 \%$ of total machining cost (Liu et al., 2018). Production of cutting tools needs many types of rare metal, including tungsten, chromium, molybdenum, vanadium, cobalt, etc. In the process of mining, smelting, forging, rolling and machining, great mineral resources and energy are used (Li et al., 2015). Consequently, the more durable and capable a cutting tool is, the more cost, resource and energy could be saved.

Unfortunately, to avoid poor surface quality, shock and vibration caused by overuse, cutting tools are normally underused, resulting in huge waste. Study showed that only $50 \sim 80 \%$ of cutting tool life was rationally used (Zhou and Xue, 2018). American companies e.g. Kennamtal believed that up to $30 \%$ cutting tool life could be saved (Liu et al., 2018). European and Japanese manufacturers used less than or equal to $70 \%$ of cutting tool life (Martinova et al., 2012). Inevitably, underuse may lead to cutting tool life reduction, machining cost increment, and cutting tool utilization waste (as shown in Fig. 1). Although a cutting tool has potential utilization, how to unleash it is very tough. The lack of reliable support puts cutting tool life extension, and material removal rate (MRR) or material removal volume (MRV) improvement at a great risk. 


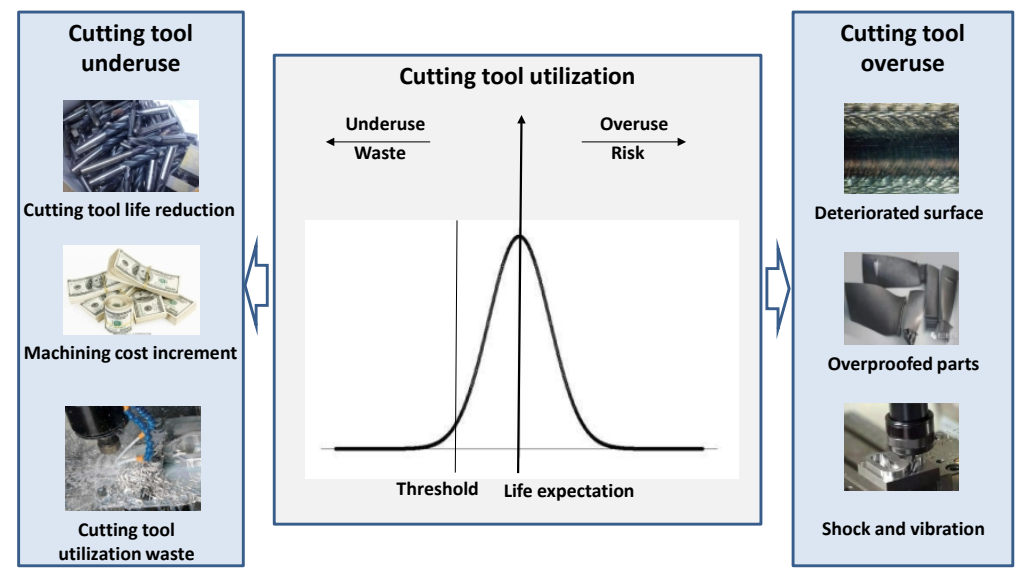

Fig. 1 Paradox in cutting tool utilization

Under a certain machining condition (MC), every cutting tool's utilization could be extended further to reduce cutting tool consumption, to save machining cost, and to enhance sustainability (Schultheiss et al., 2013). However, cutting tools' lives vary greatly, even if they are the same type produced by the same manufacturer. Within a single batch, tool life of Russian production may vary widely by $15-40 \%$ (Martinova et al., 2012). Moreover, every cutting tool has its unique and dynamic wear curve. Without quantized uncertainty, cutting tool remaining useful life (RUL) prediction is not reliable enough for cutting tool selection or replacement decision-making (Sun et al., 2018).

Under various MCs, cutting tools could be used further by optimizing machining parameters for higher efficiency. Then, fewer cutting tools are needed to finish assigned machining tasks. However, multiple variables affect the cutting tool wear curve. Due to the lack of a reliable basis, machining parameter optimization for higher efficiency faces a huge barrier.

This work aims to enhance the sustainability by making cutting tool more durable and capable. A cutting tool could be used based on its specific RUL prediction. Machining parameters could be optimized to improve cutting tool utilization. Benefit and risk could be balanced by assigning a proper confidence level. Cutting tool sustainability could be improved in economic, environmental and social dimensions.

The rest of this paper is organized as follows. Section 2 presents a brief review of literature related to cutting tool sustainability and RUL prediction. Section 3 proposes the sustainability improvement approach based on RUL prediction. Several sub-sections are included to address some key issues, respectively. An experimental study is presented in Section 4, which is followed by concluding remarks in Section 5.

\section{Literature review}

\subsection{Cutting tool sustainability assessment}

Due to scarcity of natural resources and increasingly strict regulations, sustainable manufacturing has become a hot topic both in academia and industry (Huang and Badurdeen, 2017). Metrics for sustainable manufacturing were investigated in economic, social, and environmental dimensions of the triple bottom line (TBL) concept (Lu et al., 2012; Reich-Weiser et al., 2013; Peralta et al., 2017). Manufacturing sustainability was also evaluated based on the correlation between TBL dimensions and balanced scorecard perspectives (Junior et al., 2018). Cutting tool sustainability is included in manufacturing sustainability, but related research is very limited. 
Cutting tools' economic sustainability was normally assessed by using cutting tool cost. However, cutting tool cost accounted for a small share of machining cost (Zhou and Xue, 2018). On the other hand, the frequency of cutting tool replacement affected downtime of machine tools. Then, machining efficiency was considered in cutting tools' economic sustainability assessment (Astakhov, 2019).

The concept of life cycle assessment (LCA) or life cycle sustainability assessment (LCSA) (Gbededo et al., 2018) was used in cutting tool's environmental sustainability assessment. Production of cutting tools needed both plenty of energy and mineral resources, when huge carbon emission was produced (Yi et al., 2015; Zhou et al., 2017). For example, tungsten is a rare and non-renewable metal. Approximately half of the tungsten in the world was consumed to produce carbide cutting tools (Schultheiss et al., 2013). Tungsten embodied material energy $400 \mathrm{MJ} / \mathrm{kg}$. Production of a carbide insert consumed 1-2 MJ energy on average (Gutowski et al., 2009). If the energy footprint of its material was considered, the energy consumption was 5.3 MJ (Rajemi et al., 2010). Environmental impact rating of cutting tool production was $33.7478 \mathrm{kgCO}_{2} / \mathrm{kg}$ (Hegab et al., 2018). Production of cutting tools consumed huge resource and energy (Loglisci et al., 2013). The more cutting tools were used, the poorer the environmental sustainability was. In the machining process, worn cutting tools were believed to increase energy consumption.

Normally, social sustainability is the ability of a social system, such as a country, to function at a defined level of social well-being indefinitely (Lu et al., 2011). Regarding an enterprise, social sustainability relates to personnel health, operational safety, stakeholder engagement (Huang and Badurdeen, 2017), risk assessment (Reich-Weiser et al., 2013), and so on. To the best of the authors' knowledge, study on social sustainability of cutting tools is rare.

\subsection{Cutting tool life estimation and RUL prediction}

Cutting tool life extension should be based on accurate life estimation. In the past few years, these topics attracted great attentions. Traditional cutting tool life estimation used statistic models, such as normal distribution, lognormal distribution, and Weibull distribution. In addition, Bernstein distribution function was also used as a practical approach to the cutting tool reliability improvement (Astakhov, 2010).

Normally, cutting tool life was measured in the time dimension. Although many cutting tool manufacturers have developed cutting tools with longer life at higher cutting speeds, few manufacturers have worked to develop cutting tools that have less variability in life (Black and Kohser, 2007). In a machining process, unpredictable cutting tool failure is extremely costly. Tool life variability may lead to low productivity and high machining cost. Then, cutting tool life variability under a certain MC should be clarified and limited as much as possible (Astakhov, 2014). However, tool wear was no longer considered to be the primary criterion of failure (Astakhov, 2014). Instead, machining accuracy, surface roughness, or machining efficiency might be the primary concern.

The cutting tool utilization was considered to be the ability to achieve the pre-set quality requirements for a given material efficiently. A cutting tool's time-varying utilization can be measured by RUL. In the past few years, a significant amount of research has been done to develop cutting tool RUL prediction models (Lei et al., 2018). For example, by using force, vibration and acoustic emission (AE) signals (Zhou and Xue, 2018), cutting tool RUL was predicted based on the operational reliability assessment and the back propagation neural network (BPNN) (Sun et al., 2016). Cutting tool RUL was also estimated based on neuro fuzzy logic, support vector regression (SVR) (Gokulachandran and Padmanaban, 2018) and hidden Markov model (HMM) (Kumar et al., 2019). By using wavelet packet transform and extreme learning machine (ELM), a nonlinear regression model was built for tool RUL prediction (Laddada et al., 2017)Error! Reference source not found.. The proportional hazards model and the logical analysis of data were used and compared in cutting tool RUL prediction of titanium metal matrix composites turning (Shaban and Yacout, 2016). Moreover, an adaptive resampling-based particle filtering for cutting tool RUL prediction was proposed to overcome the sample impoverishment problem in sequential importance resampling (Wang and Gao, 2015). However, results of these machining learning-based 
models were not easy to interpret with compelling physical meanings. There were also challenges in determining thresholds, extracting features, and solving over-fitting issues. Although the prediction results may be more accurate, the reliability and interpretability are vague. Without quantized uncertainty, a cutting tool usage decision may be made at unknown risk.

To address the uncertainty of prediction, stochastic process was used to model degradation process and predict RUL. Wiener process, i.e., Brownian motion with a linear drift, was one of the most popular ones (Si et al., 2017; Wang and Tsui, 2018). Due to its excellent mathematical properties and physical interpretations, Wiener process could provide a good description of systems' non-linear, non-monotonic, and dynamic characteristics (Zhang et al., 2018). Wiener process could model a degradation state as an infinitely divisible process. The explicit distribution of the first hitting time (FHT) of a Wiener process could be resolved (Huang et al., 2017). Therefore, a Wiener-based cutting tool wear curve and RUL prediction approach was put forward (Sun et al., 2018). However, the non-linear wear curve was modelled as several segmented linear ones. Although the predicted results approximated the measured ones well, huge absolute errors still existed at the beginning. A real non-linear cutting tool wear curve is more reasonable.

\subsection{Cutting tool utilization improvement}

If every cutting tool's utilization could be used precisely, the cost of labour and machine stoppage will be decreased greatly (Astakhov, 2010). In order to make most use of every cutting tool, some decisions should be made prior to the machining process, e.g. whether a cutting tool can finish a machining task with minimum life waste. In industry, life expectation of a group of cutting tools was estimated based on some machining tests. Every cutting tool in this group was used according to a unified life bound, regardless the differences among them. Then, most cutting tools were used conservatively. In fact, every cutting tool is unique, and every cutting tool wear curve is dynamic and time varying. Such a unified bound is not suitable for smart and sustainable manufacturing.

Moreover, cutting tool replacement decisions should also be made during the machining process, e.g. when a cutting tool's failure is around the corner. Xu and Cao (2015) investigated periodic tool replacement decision-making in the production process to reduce cost, improve production efficiency and energy efficiency. They also proposed a partially observable Markov model for dynamic tool replacement decision-making considering the quality failure probability and cutting energy consumption. However, replacement decision-making should be made for every single cutting tool. In-process conditions should be analysed to improve reliability of tool replacement decision-making (Ren et al., 2018). Considering the stochastic characteristics of tool life in the machining process, a hybrid policy was developed based on the reliability function for optimising the tool replacement time, which could achieve better results for the costs of the cutting tool replacement, cutting tool failures, machine tool downtime and tool condition monitoring (Zaretalab et al., 2019).

By optimizing machining parameters, cutting tool lives could also be extended. By reducing friction between cutting tools and workpieces considerably, cutting fluid improved surface roughness and cutting tool lives (Debnath et al., 2014). Compared with the traditional flood cooling system, some sustainable techniques, including minimum quantity lubrication (MQL) (Mia et al, 2018), cryogenic cooling, etc., were adopted to improve cutting tool durability (Shokrani et al., 2012). MQL was proved to have lower tool wear and surface roughness value (Sakharkar et al., 2018). However, LCA should be used to prepare a strong database for sustainable manufacturing (Chetan et al., 2015). Although optimization of machining parameters, including feed rate, cutting depth and cutting speed, were believed to improve cutting tool sustainability, how to make a trade-off between them was a big challenge.

In summary, cutting tool sustainability could be improved by using every cutting tool according to its specific RUL prediction. In order to balance the benefits and risks, more reliable decisions about cutting tool selection and machining parameter optimization should be made. However, studies regarding its 
implementation are very limited and insufficient. Some significant topics should be investigated further to enhance cutting tool sustainability. This paper aims to bridge these gaps.

\section{Cutting tool sustainability enhancement approach based on cutting tool RUL prediction}

The proposed approach to cutting tool sustainability enhancement based on RUL prediction is shown in Fig. 2. The approach includes the following three steps.

1) Cutting tool RUL prediction. Based on non-linear Wiener process and historical tool wear data, a cutting tool RUL prediction model is built for every MC. A cutting tool RUL prediction comes with quantized probability distribution function (PDF) and cumulative distribution function (CDF). However, every cutting tool has its unique wear curve. Under a certain MC, a cutting tool's wear trend can be predicted considering its wear history. Its RUL variability can also be predicted under a certain confidence level. Similar cutting tool wear trend and RUL prediction models can also be built for various MCs.

2) Cutting tool selection and machining parameter optimization. In order to use every cutting tool further at controllable risk, a cutting tool can be matched with a suitable machining task according to its specific RUL prediction, rather than a unified one. Machining parameters can also be optimized based on RUL prediction under various MCs. The benefit and risk are balanced by using a confidence level.

3) Cutting tool sustainability assessment and comparison. Based on TBL, cutting tool sustainability is assessed in economic, environmental and social dimensions. MRR, MRV, cutting tool cost, carbon emission and risk are evaluated and compared.

Therefore, cutting tool RUL prediction, cutting tool selection decision-making, machining parameters optimization and cutting tool sustainability assessment are vital to this approach. The following subsections address these issues in detail.

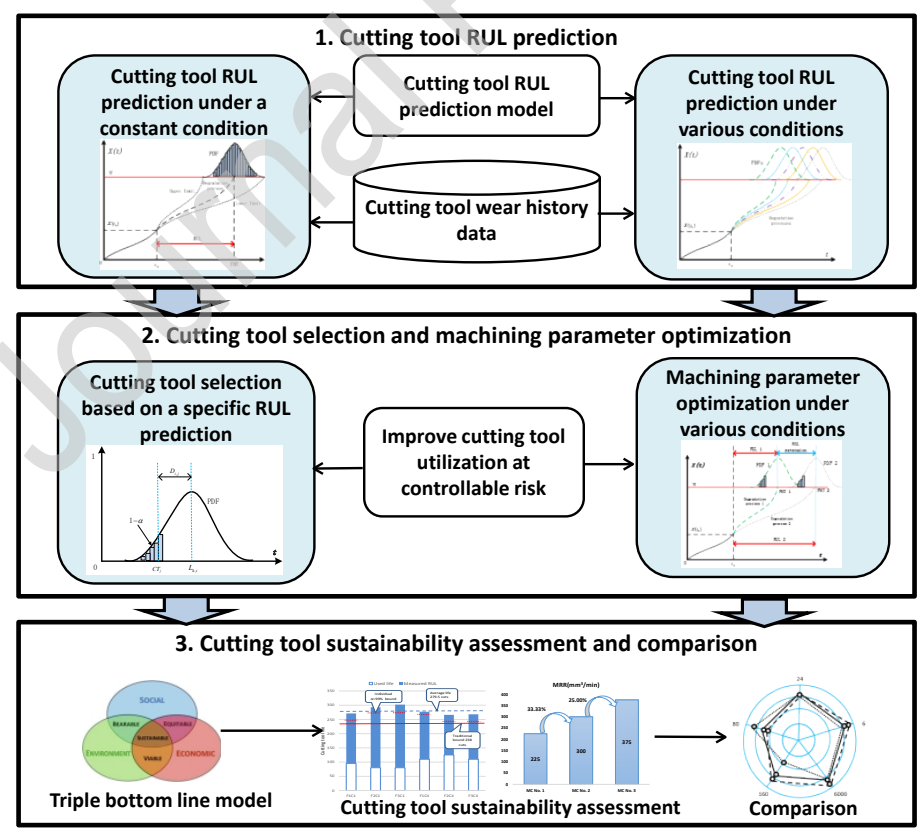

Fig. 2 Approach to cutting tool sustainability enhancement based on RUL prediction

\subsection{Cutting tool RUL prediction}

Without loss of generality, flank wear $(V B)$ is considered to be the primary criterion of cutting tool failure in this work. Normally, a cutting tool's life ends when its $V B$ value exceeds the predefined wear criterion $w$. Cutting tool wear is a non-linear stochastic process $\{X(t), t \geq 0\}$ regarding time ${ }^{t}$. RUL of a 
cutting tool at time $t_{k}$ is denoted by $T_{k}$. According to the definition of FHT, it is the duration between time $t_{k}$ and the time that $V B$ value exceeds $w$ for the first time, as shown in Eq. (1).

$$
T_{k}=\inf \left\{t: X\left(t+t_{k}\right) \geq w \mid X\left(t_{k}\right)<w, t>0\right\}
$$

The CDF $P_{T}(t)$ gives the area under the PDF $f_{T}(t)$ from 0 to time $T$, and can be calculated by Eq. (2).

$$
P_{T}(t)=\int_{0}^{T} f_{T}(t) d t
$$

By using historical data, the wear curve of a cutting tool type under a certain MC can be modelled (Sun et al., 2018). As shown in Fig. 3, RUL regarding state $X_{\left(t_{k}\right)}$ can also be estimated with quantized PDF and CDF. Under a specific confidence level $\alpha$, the upper bound and the lower bound can be resolved.

Similarly, wear curves, RULs, PDFs and CDFs under various MCs (shown in Fig. 4) can also be modelled or calculated. The more data are used, the more reliable the RUL prediction results are.

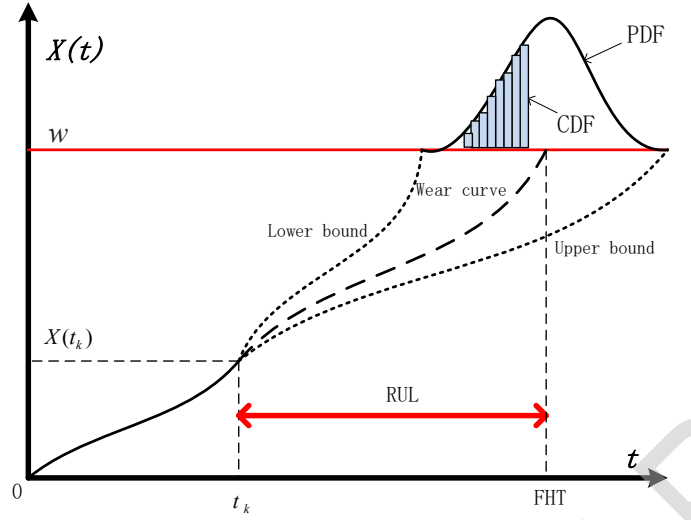

Fig. 3 A wear curve under a certain $\mathrm{MC}$

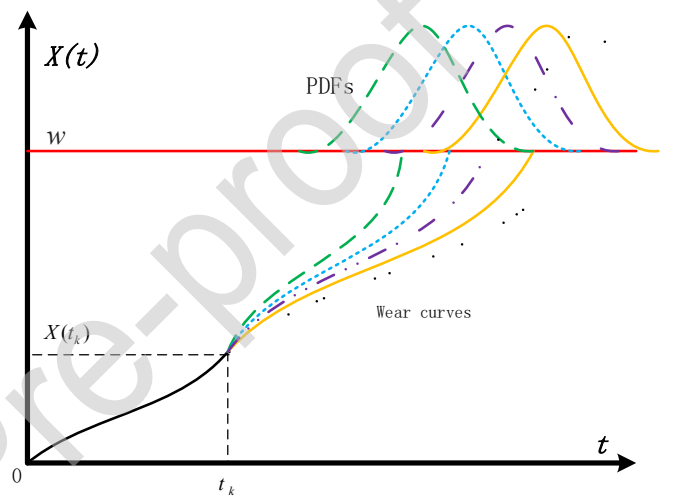

Fig. 4 Wear curves under various MCs

3.2 Cutting tool selection based on a specific RUL prediction

Prior to a machining task, a right cutting tool should be selected according to its specific RUL. Some cutting tools of the pre-defined types with different conditions and RULs are candidates. A reliable decision could be made based on cutting tool RUL prediction. In order to maximise the use of every cutting tool at controllable risk, the confidence level $\alpha$ is used. To finish machining task $j$, CDF of cutting tool $i$ regarding $C T_{j}$, denoted by $P_{T_{k, i}}\left(C T_{j}\right)$, should satisfy the following constraint.

$$
P_{T_{k, i}}\left(C T_{j}\right)=\int_{t_{k}}^{t_{k}+C T_{j}} f_{T_{k, i}}(t) d t \leq 1-\alpha
$$

Here, $C T_{j}$ is time duration of task $i . T_{k, i}$ is RUL of cutting tool $i$ at time ${ }_{t_{k}}$. The difference between $C T_{j}$ and $T_{k, i}$, denoted by $D_{i, j}$, stands for the margin. Then, the risk of a cutting tool selection decision is calculable. RUL waste of a cutting tool is also measurable and controllable. By minimizing $D_{i, j}$ and satisfying Eq. (3), every cutting tool is matched with a right task. Interrelationship among $\alpha, C T_{j}$ and $D_{i, j}$ is shown in Fig. 5. Obviously, PDF affects the margin greatly. The benefit and risk can be balanced by adjusting the confidence level $\alpha$. 


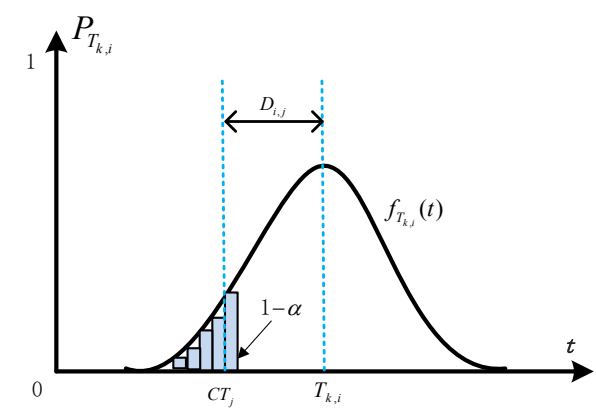

Fig. 5 Pre-task RUL prediction and probability

\subsection{Machining parameter optimization considering various MCs}

Cutting tool wear curves vary greatly under different MCs. Machining parameters could be optimized to extend a cutting tool's life. Without loss of generality, some factors, such as machine tool, workpiece material and cutting fluid, are regarded as constants. Feed speed $\left(f / \mathrm{mm} \cdot \mathrm{min}^{-1}\right)$, cutting width $\left(a_{e} / \mathrm{mm}\right)$, cutting depth $\left(a_{p} / \mathrm{mm}\right)$, etc., are considered as key machining parameters in this work. Here, an MC means a combination of them. As Fig 6 shows, at time ${ }_{t_{k}}$, two MCs result in different cutting tool wear curves, FHTs, RULs and PDFs. Compared with MC 1, cutting tool life could be extended greatly by MC 2 . Then, the wear curve 2 is better than wear curve 1 under the same confidence level $\alpha$. However, cutting tool life extension may lead to lower machining efficiency. To improve the benefit systematically, an MC should be evaluated according to the sustainability assessment metrics.

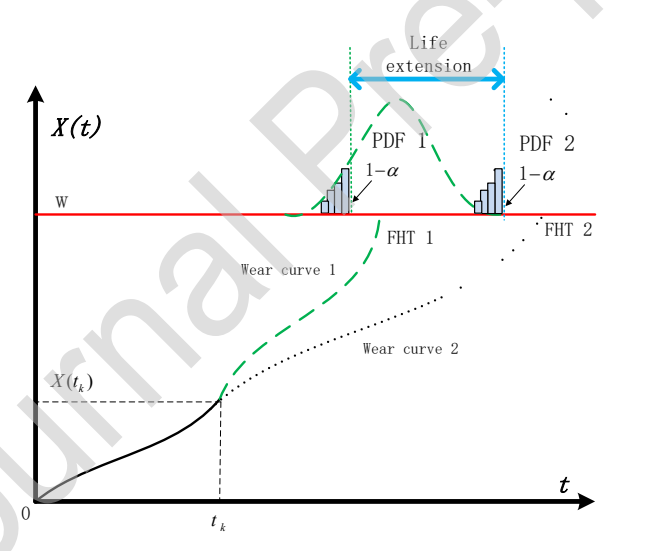

Fig. 6 Cutting tool wear curves under different MCs

\subsection{Cutting tool sustainability assessment and comparison}

According to the TBL, cutting tool sustainability can be assessed in economic, environmental and social dimensions.

1) Economic sustainability assessment

The economic sustainability is assessed by cutting tool life and cost. Compared with traditional mode, cutting tool selection based on a specific RUL prediction is liable to maximise the use of every cutting tool. Due to life extension, fewer cutting tools are used to fulfil the same machining time requirement and cutting tool cost could be reduced. Moreover, cutting tool life extension leads to less cutting tool replacement, which means more machining time. The equipment utilization ratio can be increased too.

Cutting tool life varies under different MCs. Machining parameter optimization may extend or shorten a cutting tool's life. It can also change MRR, a measurement of machining efficiency. Under a certain MC, MRR can be calculated by Eq. (4). 


$$
M R R=f \cdot a_{e} \cdot a_{p}
$$

Cutting tool life and MRR affect a cutting tool's utilization, which can be evaluated by MRV. As to cutting tool $i$, within time duration of machining task ${ }_{j}$, MRV is calculated by Eq. (5).

$$
M R V_{i, j}=M R R_{j} \cdot C T_{j}
$$

Cost of cutting tool $i$ can be shared by material it removes as in Eq. (6)

$$
C C_{i}=\operatorname{Cost}_{i} / M R V_{i}
$$

where $C_{C C_{i}}$ is cost sharing of cutting tool $i$, Cost $_{i}$ is cost of cutting tool $i$, and ${ }_{M R V_{i}}$ is the total MRV of cutting tool $i$.

2) Environmental sustainability assessment

The environmental sustainability is assessed by carbon emission, which was calculated by using weight of cutting tool material (Rajemi et al., 2010; Li et al., 2015; Hegab et al., 2018). Carbon emission of cutting tool $i$ is shared by its total life as in Eq. (7)

$$
C E_{i}=F_{c e} W_{i} / L_{i}
$$

where $C E_{i}$ is carbon emission sharing of cutting tool $i, F_{c e}$ is the carbon emission factor, $W_{i}$ is the mass of cutting tool $i$, and ${ }_{L}$ is life of cutting tool $i$. If a cutting tool's life is extended, carbon emission per machining time could be decreased.

Carbon emission in the production process of cutting tool $i$ can also be shared by material it removes as in Eq. (8)

$$
C E_{i}=F_{c e} W_{i} / M R V_{i}
$$

If MRV of cutting tool $i$ is improved by machining parameter optimization, carbon emission per material volume could be decreased. Therefore, cutting tool environmental sustainability could be improved by enhancing cutting tool durability and capability.

3) Social sustainability assessment

The social sustainability is assessed by social development and life quality of the employees. Traditionally, operators select cutting tools based on experience at their own risks. It is quite conservative and arbitrary to some extent. Cutting tool life extension increases the uncertainty and the risk. Fortunately, cutting tool selection based on a specific RUL prediction comes with a quantized confidence level $\alpha$, which makes the cutting tool usage decision-making more reliable. Machining quality could be guaranteed at controllable risk without artificial factors. Operators are free from cutting tool selection decision-making. Moreover, cutting tool life extension reduces cutting tool replacement frequency, which also decreases operators' workload. Then, non-productive time can be reduced, and cutting tools can be used precisely to avoid unexpected downtime and scrapped components.

In summary, cutting tool sustainability could be improved by cutting tool selection based on a specific RUL prediction and machining parameter optimization considering various machining parameters. In order to assess and compare cutting tool sustainability, some significant metrics are selected and listed in Table 1.

Table 1 cutting tool sustainability assessment metrics 


\begin{tabular}{|c|c|c|}
\hline & $\begin{array}{l}\text { Cutting tool selection based } \\
\text { on a specific RUL } \\
\text { prediction }\end{array}$ & $\begin{array}{l}\text { Machining parameter optimization } \\
\text { considering various machining } \\
\text { parameters }\end{array}$ \\
\hline $\begin{array}{l}\text { Economic } \\
\text { sustainability }\end{array}$ & $\begin{array}{ll}\text { - } & \text { Cutting tool RUL } \\
\text { - } & \text { Cutting tool cost } \\
\text { sharing } & \\
\text { - } & \text { MRV } \\
\end{array}$ & $\begin{array}{ll}- & \text { Cutting tool RUL } \\
- & \text { Cutting tool cost sharing } \\
\text { - } & \text { MRR } \\
& \text { MRV } \\
\end{array}$ \\
\hline $\begin{array}{l}\text { Environmental } \\
\text { sustainability }\end{array}$ & $\begin{array}{l}\text { - Carbon emission per } \\
\text { machining time }\end{array}$ & $\begin{array}{ll} & \begin{array}{l}\text { Carbon emission per material } \\
\text { volume }\end{array}\end{array}$ \\
\hline Social sustainability & Risk control & 1 \\
\hline
\end{tabular}

\section{Experimental study}

4.1 Cutting tool sustainability assessment under a constant machining condition

In order to assess cutting tool sustainability under a constant MC, the dataset provided by the $2010 \mathrm{PHM}$ Data Challenge (PHM, 2010) is used. The experimental setup is given in Table 2.

Table 2 Experimental setup A

\begin{tabular}{|c|c|}
\hline Name & Description/content \\
\hline Machine tool & Röders Tec RFM 760 CNC machine \\
\hline Workpiece & stainless steel (HRC52) \\
\hline Cutting tool & three-flute tungsten carbide cutters \\
\hline Spindle speed & 10400 RPM \\
\hline Feed speed $(f)$ & $1555 \mathrm{~mm} / \mathrm{min}$ \\
\hline Cutting width $\left(a_{e}\right)$ & $0.125 \mathrm{~mm}$ \\
\hline Cutting depth $\left(a_{p}\right)$ & $0.2 \mathrm{~mm}$ \\
\hline Cutting cycles & 315 cuts \\
\hline Cutting length & $108 \mathrm{~mm} / \mathrm{cut}$ \\
\hline MRR & $38.875 \mathrm{~mm}^{3} / \mathrm{min}\left(2.7 \mathrm{~mm}^{3} / \mathrm{cut}\right)$ \\
\hline Wear criterion & $V B \geqslant 0.15 \mathrm{~mm}$ \\
\hline
\end{tabular}

Cutting tools used in this case are named $\mathrm{C} 1, \mathrm{C} 2, \mathrm{C} 3, \mathrm{C} 4, \mathrm{C} 5$ and $\mathrm{C} 6$ respectively. Every cutting tool was used for about 315 cut cycles under the same machining condition. $V B$ values of cutting tool $C 1, C 4$ and $\mathrm{C} 6$ were recorded after every cut cycle. Each flute is regarded as a specific one. Flute 2 of cutter $\mathrm{C} 1$ is named $\mathrm{F} 2 \mathrm{C} 1$, and other flutes are named similarly. The carbon emission factor of cutting tool production was $29.6 \mathrm{kgCO}_{2} / \mathrm{kg}$ ( $\mathrm{Li}$ et al., 2015). Carbon emission for a flute production is $266.4 \mathrm{~g}$, because the average weight of a flute is $9 \mathrm{~g}$ (Rajemi et al., 2010).

Regarding flutes $\mathrm{F} 1 \mathrm{C} 1, \mathrm{~F} 2 \mathrm{C} 1, \mathrm{~F} 3 \mathrm{C} 1, \mathrm{~F} 1 \mathrm{C} 4, \mathrm{~F} 2 \mathrm{C} 4$ and $\mathrm{F} 3 \mathrm{C} 4$, the maximum life, average life and minimum life are 302 cuts, 279.500 cuts and 266 cuts, respectively. In order to use cutting tools at controllable risk, $85 \%$ of average life (238 cuts) is set as the wear criterion for all flutes, according to engineering experience. If this unified bound is used, the sustainability is assessed as follows.

1) Economic sustainability assessment: The total RUL is 825 cuts. The total MRV is $2229 \mathrm{~mm}^{3}$.

2) Environmental sustainability assessment: Carbon emission sharing is $1.121 \mathrm{~g} / \mathrm{cut}$.

3) Social sustainability assessment: To some extent, the wear criterion is arbitrary. Cutting tools may be used conservatively.

If every cutting tool is used based on its specific RUL prediction, the situation is different. Under the confidence level $\alpha=99 \%$, the upper bound of every cutting tool life is obtained and given in Table 2 . The sustainability is assessed as follows. 
1) Economic sustainability assessment: The total life and total RUL are 1556 cuts and 956 cuts, respectively. The total MRV is $2581 \mathrm{~mm}^{3}$.

2) Environmental sustainability assessment: Carbon emission sharing is $1.027 \mathrm{~g} / \mathrm{cut}$.

3) Social sustainability assessment: Every cutting tool is used under the confidence level $\alpha=99 \%$. Cutting tools could be used further at measurable and controllable risk.

Detailed comparison between a unified bound and some specific bounds is given in Fig. 7 and Table 3 .

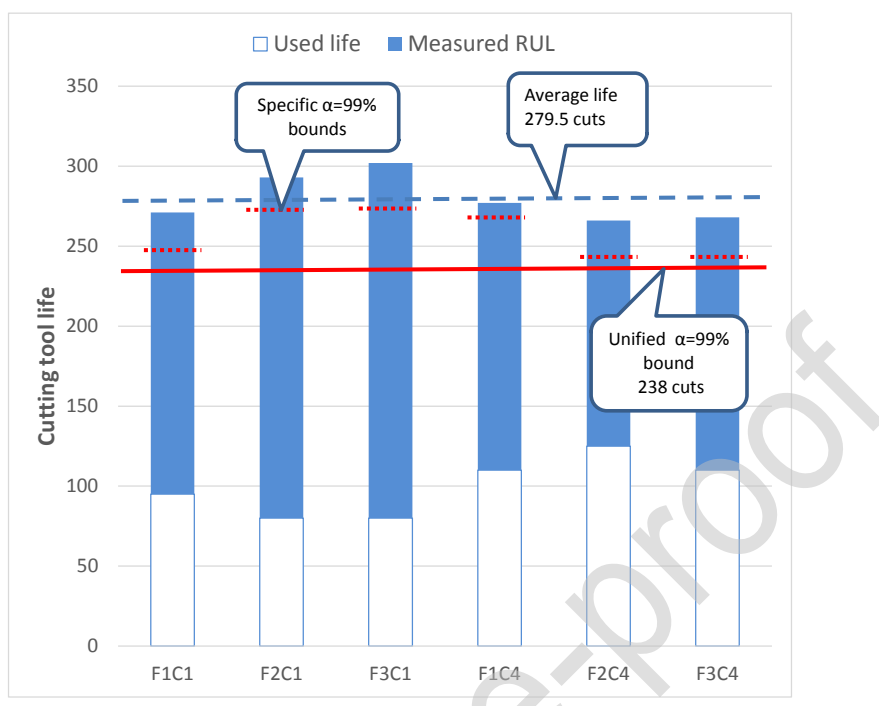

Fig. 7 Life and RUL comparison

Table 3 Detailed information of every flute

\begin{tabular}{|l|c|c|c|c|c|c|c|}
\hline & F1C1 & F2C1 & F3C1 & F1C4 & F2C4 & F3C4 & Total \\
\hline Life Used (cuts) & 95 & 80 & 80 & 110 & 125 & 110 & 600 \\
\hline Traditional bound (cuts) & 237.6 & 237.6 & 237.6 & 237.6 & 237.6 & 237.6 & 1426 \\
\hline Available RUL (cuts) & 142.6 & 157.6 & 157.6 & 127.6 & 112.6 & 127.6 & 825 \\
\hline Measured RUL (cuts) & 176 & 213 & 222 & 167 & 141 & 158 & 1077 \\
\hline Predicted RUL (cuts) & 172 & 210 & 211 & 195 & 142 & 157 & 1087 \\
\hline$\alpha=99 \%$ bound (cuts) & 151 & 194 & 193 & 162 & 120 & 135 & 956 \\
\hline The specific bound (cuts) & 246 & 274 & 273 & 272 & 245 & 245 & 1556 \\
\hline MRV $\left(\mathrm{mm}^{3}\right.$ ) & 409 & 524 & 521 & 437 & 325 & 365 & 2581 \\
\hline
\end{tabular}

Obviously, better sustainability is achieved by using each cutting tool according to its specific RUL prediction.

1) As to economic sustainability, the total RUL is improved from 825 cuts to 956 cuts. The total MRV is improved from $2229 \mathrm{~mm}^{3}$ to $2581 \mathrm{~mm}^{3}$ by $15.81 \%$.

2) As to environmental sustainability, carbon emission for a flute production is decreased from $1.21 \mathrm{~g} / \mathrm{cut}$ to $1.027 \mathrm{~g} /$ cut by $8.39 \%$.

3) As to social sustainability, cutting tools are used further at precisely controlled risk.

In Fig. 8, a radar diagram is used to compare two situations vividly. To present in "the higher the better" manner, the reciprocal of carbon emission (cut/g) is used in the diagram. It can be seen that cutting tool selection based on the specific bounds is more sustainable than the unified bound. 


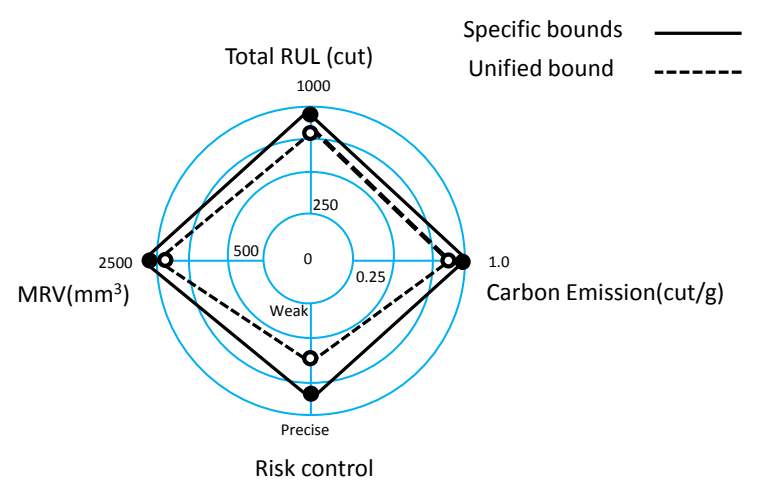

Fig. 8 Sustainability assessment and comparison

\subsection{Cutting tool sustainability assessment considering various machining conditions}

In order to assess cutting tool sustainability under various MCs, a series of machining experiments are carried out. The experimental setup is given in Table 4 .

Table 4 Experimental setup B

\begin{tabular}{|l|l|l|}
\hline Name & Description & Memo \\
\hline Machine tool & JDCT1200E_A12S & 3-axis, max power 10kw \\
\hline Cutting tool & S4-GH1022075-Ø10*25*75 & $\Phi 10 \mathrm{~mm}$, flat-end, 4 edges, CNY 240 each \\
\hline Workpiece & $45($ ASTM 1045) & $70 \mathrm{~mm} * 50 \mathrm{~mm} * 50 \mathrm{~mm}, \mathrm{HB} 200$ \\
\hline Tool microscope & CW0505 & $5+\mathrm{L} / 20 \mu \mathrm{m}$ \\
\hline
\end{tabular}

In rough machining, material should be removed as much as possible. MC No. 1 is designed according to the real MC in factory. Three cutting tools are used in the machining experiments. According to above discussion, in-process data is collected to build the degradation model and predict RUL under MC No. 1. As shown in Table 5, although the spindle speed (4000 RPM) is relatively high, a low feed speed (150 $\mathrm{mm} / \mathrm{min}$ ) balances the MRR which is $225 \mathrm{~mm}^{3} / \mathrm{min}$. Under the $\alpha=99 \%$ confidence level, cutting tool RUL is $47.07 \mathrm{~min}$, which leads to $10113.75 \mathrm{~mm}^{3} \mathrm{MRV}$. Carbon emission and cutting tool cost are 0.105 $\mathrm{g} \mathrm{CO}_{2} / \mathrm{mm}^{3}$ and $0.024 \mathrm{CNY} / \mathrm{mm}^{3}$, respectively.

To improve machining efficiency, the feed speed is increased from $150 \mathrm{~mm} / \mathrm{min}$ in MC No. 1 to 200 $\mathrm{mm} / \mathrm{min}$ in MC No. 2. To extend cutting tool life, spindle speed is decreased to $2000 \mathrm{RPM}$. As shown in Fig. 9, MRR is increased to $300 \mathrm{~mm}^{3} / \mathrm{min}$ by $33.33 \%$. During the machining, the data obtained by using three cutting tools is adopted to build the cutting tool wear curve and predict RUL. Under the $\alpha=99 \%$ confidence level, RUL is extended to $62.39 \mathrm{~min}$ by $38.80 \%$. MRV is extended to 18717 by $85.06 \%$. Carbon emission is decreased to 0.057 by $45.96 \%$. By optimizing machining parameters, cutting tools becomes more capable and durable.

Moreover, machining efficiency can be improved further. Regarding MC No. 3, feed speed is increased up to $250 \mathrm{~mm} / \mathrm{min}$. Because spindle speed is increased to $3000 \mathrm{RPM}$, MRR is increased to $375 \mathrm{~mm} / \mathrm{min}$ by $25.00 \%$. According to the cutting tool wear curve based on three cutting tools, RUL is decreased to $50.88 \mathrm{~min}$ by $18.45 \%$ under the $\alpha=99 \%$ confidence level. Compared to MC No. 1 , cutting tool RUL is still extended by $8.09 \%$. MRV is increased to 19080 by $1.94 \%$. Carbon emission sharing and cutting tool cost sharing is decreased by $1.90 \%$. As a result, better sustainability is achieved, despite of decreased cutting tool RUL.

Table 5 Experiments for rough machining

\begin{tabular}{|c|c|c|c|}
\hline & MC No.1 & MC No. 2 & MC No. 3 \\
\hline Cutting depth (mm) & 1.5 & 1.5 & 1.5 \\
\hline Spindle speed (RPM) & 4000 & 2000 & 3000 \\
\hline
\end{tabular}




\begin{tabular}{|c|c|c|c|}
\hline Feed speed $(\mathrm{mm} / \mathrm{min})$ & 150 & 200 & 250 \\
\hline MRR $\left(\mathrm{mm}^{3} / \mathrm{min}\right)$ & 225 & 300 & 375 \\
\hline$\alpha=99 \%$ RUL bound $(\mathrm{min})$ & 47.07 & 62.39 & 50.88 \\
\hline MRV under $\alpha=99 \%$ bound $\left(\mathrm{mm}^{3}\right)$ & 10113.75 & 18717 & 19080 \\
\hline Carbon emission sharing $\left(\mathrm{g} \mathrm{CO}_{2} / \mathrm{mm}^{3}\right)$ & 0.105 & 0.057 & 0.056 \\
\hline Cutting tool cost sharing $\left(\mathrm{CNY} / \mathrm{mm}^{3}\right)$ & 0.024 & 0.013 & 0.013 \\
\hline
\end{tabular}

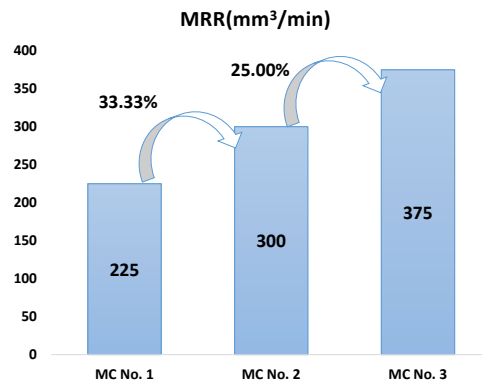

(a)

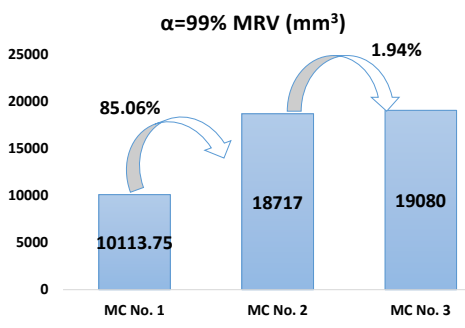

(c)

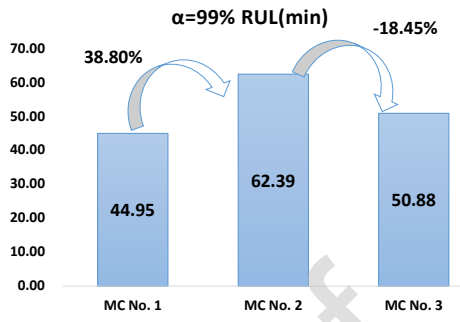

(b)

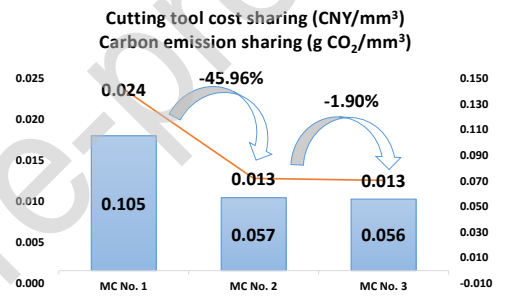

(d)

Fig. 9 Detailed sustainability comparison

Their sustainability is also compared as shown in Fig. 10. To present in "the higher the better" manner, the reciprocals of cutting tool cost sharing and carbon emission sharing are used in the diagram. It can be seen that MC No. 3 scores the highest marks in almost all cutting tool sustainability assessment metrics, except cutting tool RUL. Considering a 3\%-5\% share of cutting tool cost out of machining cost, it is reasonable to make such a trade-off for a better sustainability.

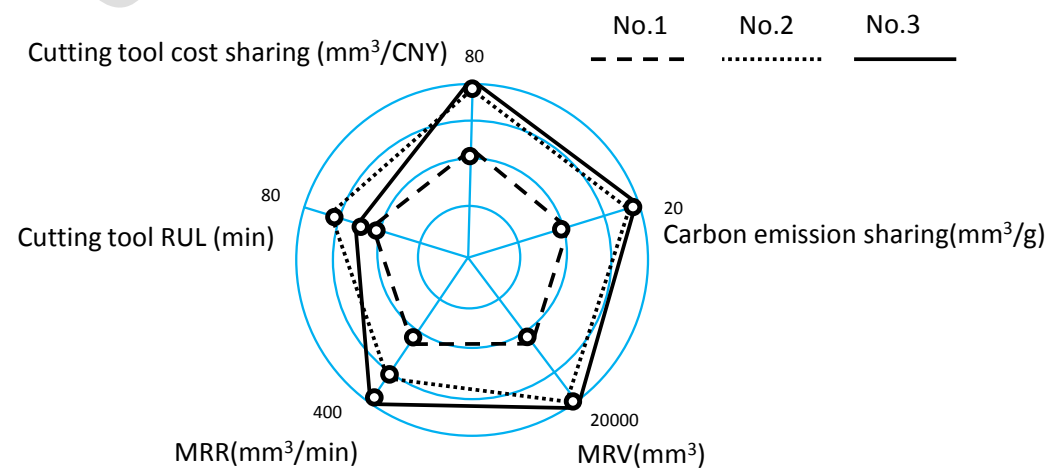

Fig. 10 Sustainability comparison in a radar map

4.3 Discussions 
According to above experimental results, the work shows a great improvement in cutting tool sustainability. Under a constant MC, a cutting tool's life can be extended according to its specific RUL prediction. PDF, CDF and confidence level $\alpha$ contribute to the balance between benefit and risk. In fact, machining sustainability improvement is more than life extension. Based on RUL prediction, machining parameters are optimized to improve MRV, and to reduce cost sharing and carbon emission sharing. As a result, cutting tool sustainability could be enhanced significantly.

However, the feasibility of the proposed method depends heavily on accuracy and reliability of cutting tool RUL prediction. A scattering PDF is meaningless for the consequent decision-making. More efforts should be made to improve the cutting tool RUL prediction model, especially in machining of a highvalue component of which quality requirement must be fulfilled. Decision of a RUL extension and an MRV improvement should be carefully made on a more reliable basis.

This work could also be expanded to a wider scope of manufacturing field, such as bearing, battery, and aero-engine overhaul, etc. For example, aero-engine overhaul should be configured for functionality recovery, cost control, environmental sustainability, etc. (Sun et al., 2017). Considering certain flight hours and thrust requirements, whether a part could be reusable is a key issue. If its RUL could be calculated by using similar approach, a selection decision could be made under a certain confidence level. Then, the part could be used further at controllable risk, and the sustainability could be enhanced greatly. However, aero-engine overhaul considers multiple objectives. A part reuse decision should be made with higher reliability. Then, this work is also applicable to decision-making of part reuse in aero-engine overhaul.

\section{Conclusions}

This paper proposes and verifies an approach to cutting tool sustainability enhancement based on a RUL prediction, and the major contributions are as follows.

- $\quad$ To reduce huge waste of cutting tools in manufacturing industry, cutting tool utilization should be improved considering sustainability. Such a goal can be achieved based on an accurate and reliable cutting tool RUL prediction, by using a historical data driven approach with a quantized uncertainty.

- Under a constant MC, a cutting tool's RUL can be extended according to its specific RUL bound, rather than a unified one. Under various MCs, machining parameters can also be optimized to improve MRR and MRV. Carbon emission sharing and cutting tool cost sharing can also be reduced. Cutting tool sustainability can be enhanced by improving cutting tool utilization at controllable risk

Although the work enhances cutting tool sustainability, some limitations call for future research. For example, machining accuracy and surface integrity could be considered to improve the cutting tool RUL prediction model's accuracy and reliability. Negative impacts of cutting tool RUL extension should be also included in cutting tool sustainability assessment. More data and cases should be used to improve the approach's feasibility and practicality.

\section{Acknowledgements}

The research is under the support of the National Natural Science Foundation of China (NSFC, No. 51875475) and the key R\&D program of Shaanxi Province (Program No. 2018ZDXM-GY-068). 


\section{References}

Astakhov, V.P., Improving Sustainability of Machining Operation as a System Endeavor Chapter 1 in book: "Measurement in Machining and Tribology" Edited by J.P. Davim, Springer, 2017, pp. 1-29

Astakhov, V.P., Cutting Tool Sustainability Chapter 2 in book: "Sustainable Manufacturing." Edited by J.P. Davim, Wiley-ISTE, 2010

Astakhov V.P., Machinability: Existing and Advanced Concepts, Chapter 1 in book: Machinability of Advanced Materials, Edited by J.P. Davim, Waley, London 2014, pp. 1-56.

Black J. T., Kohser R. A., DeGarmo's Materials and Processes in Manufacturing (Tenth Edition), John Wiley \& Sons, Inc., Hoboken, NJ, 2007

Chetan, Ghosh, S. Rao V. P. 2015. Application of sustainable techniques in metal cutting for enhanced machinability: a review. Journal of Cleaner Production, 100, 17-34.

Debnath, S., Reddy, M. M., Yi, Q. S. 2014. Environmental friendly cutting fluids and cooling techniques in machining: a review, Journal of Cleaner Production, 83, 33-47.

Gbededo, M. A., Liyanage, K., Garza-Reyes, J. A. 2018. Towards a life cycle sustainability analysis: a systematic review of approaches to sustainable manufacturing. Journal of Cleaner Production, 184, 1002-1015.

Gokulachandran, J., Padmanaban, R., 2018. Prediction of remaining useful life of cutting tools: a comparative study using soft computing methods. International Journal of Process Management \& Benchmarking, 8(2), 156-181.

Gutowski, T.G., Branham, M. S., Dahmus, J. B., Jones, A. J., Thiriez, A. 2009. Thermodynamic analysis of resources used in manufacturing processes. Environmental Science and Technology, 43(5), $1584-1590$

Hegab, H. A., Darras, B., Kishawy, H. A. 2018. Towards sustainability assessment of machining processes, Journal of Cleaner Production, 170(1), 694-703.

Huang A., Badurdeen F. 2017. Sustainable Manufacturing Performance Evaluation: Integrating Product and Process Metrics for Systems Level Assessment. Procedia Manufacturing, 8, 563-570.

Huang, Z., Xu, Z., Ke, X., Wang, W., Sun, Y., 2017. Remaining useful life prediction for an adaptive skew-wiener process model, Mechanical Systems and Signal Processing, 87, 294-306.

Junior A. N., Oliveira, M. C., Helleno, A. L. 2018. Sustainability evaluation model for manufacturing systems based on the correlation between triple bottom line dimensions and balanced scorecard perspectives. Journal of Cleaner Production, 190, 84-93.

Kumar, A., Chinnam, R. B., Tseng, F. 2019. An HMM and polynomial regression based approach for remaining useful life and health state estimation of cutting tools. Computers \& Industrial Engineering, 128, 1008-1014

Laddada, S., Benkedjouh, T., Si-Chaib, M. O., Drai, R., 2017. A data-driven prognostic approach based on wavelet transform and extreme learning machine, in International Conference on Electrical Engineering, Boumerdes, Algeria, Oct. 29-31, 2017

Lei, Y., Li, N., Guo, L., Li, N., Yan, T., Lin, J., 2018. Machinery health prognostics: a systematic review from data acquisition to RUL prediction. Mechanical Systems \& Signal Processing, 104, 799-834.

Li, C., Y. Tang, L. Cui, and P. Li. 2015. A Quantitative Approach to Analyze Carbon Emissions of CNCBased Machining Systems. Journal of Intelligent Manufacturing 26: 911-922. doi:10.1007/s10845013-0812-4

Liu, C., Li, Y., Hua, J., Lu, N., Mou, W. 2018. Real-time cutting tool state recognition approach based on machining features in NC machining process of complex structural parts. International Journal of Advanced Manufacturing Technology, 97(2), 229-241.

Loglisci, G., Priarone, P., C., Settineri, L., 2013. Cutting tool manufacturing: a sustainability perspective, $11^{\text {th }}$ global conference on sustainable manufacturing, September 23-25, Berlin, Germany, 252-257.

Lu, T. , Gupta, A. , Jayal, A. D. , Badurdeen, F. , Feng, S. C. , \& Jr, O. W. D. , et al. 2011. A Framework of Product and Process Metrics for Sustainable Manufacturing. Springer Berlin Heidelberg. 331336

Lu, T., Rotella, G., Feng, S. C., Badurdeen, F., Dillon, O. W., K. Rouch; Jawahir, I. S. 2012. MetricsBased Sustainability Assessment of a Drilling Process. Sustainable Manufacturing. Edited by Günther Selger, Springer Berlin Heidelberg. 59-64.

Martinova, L. I., Grigoryev, A. S., Sokolov, S. V. 2012. Diagnostics and forecasting of cutting tool wear at CNC machines. Automation and Remote Control, 73(4), 742-749.

Mia, M., Gupta, M. K. , Singh, G. , Królczyk, Grzegorz, \& Pimenov, D. Y. . 2018. An approach to cleaner production for machining hardened steel using different cooling-lubrication conditions. Journal of Cleaner Production, 187, 1069-1081

Peralta, M. E., Bárcena, M. M., González, F. A. 2017. On the sustainability of machining processes. 
proposal for a unified framework through the triple bottom-line from an understanding review. Journal of Cleaner Production, 142, 3890-3904.

PHM Society Conference Data Challenge, https://www.phmsociety.org/competition/phm/10, (accessed 17 December 2017).

Rajemi, M. F., Mativenga, P. T., Aramcharoen, A. 2010. Sustainable machining: selection of optimum turning conditions based on minimum energy considerations. Journal of Cleaner Production, 18(10), 1059-1065.

Reich-Weiser, C., Simon, R., Fleschutz, T., Yuan, C., Vijayaraghavan, A., Onsrud, H. 2013. Metrics for green manufacturing. Green Manufacturing, 49-81. Edited by David A Dornfeld, Springer, New York, 2013.

Ren, S., Zhang, Y., Liu, Y., Sakao, T., Huisingh, D., \& Almeida, C. M. V. B. 2019. A comprehensive review of big data analytics throughout product lifecycle to support sustainable smart manufacturing: a framework, challenges and future research directions. Journal of Cleaner Production, 210, 1343-1365.

Sakharkar, S. N., Pawade, R. S. 2018. Effect of machining environment on turning performance of austempered ductile iron. CIRP Journal of Manufacturing Science and Technology, 22, 49-65.

Schultheiss, F., Zhou, J., Gröntoft, E., Ståhl, J. 2013. Sustainable machining through increasing the cutting tool utilization. Journal of Cleaner Production, 59, 298-307.

Shaban, Y., Yacout, S., 2016. Cutting tool remaining useful life during turning of metal matrix composites, in Reliability and Maintainability Symposium, IEEE, Tucson, AZ, USA, Jan. 25-28, 2016.

Shokrani, A., Dhokia, V., Newman, S. T. 2012, Environmentally conscious machining of difficult-tomachine materials with regard to cutting fluids, International Journal of Machine Tools and Manufacturing, 57, 83-101.

Si, X.S., Hu, C.H., Zhang Z.X., 2017. Data-Driven Remaining Useful Life Prognostics Techniques. Beijing, China: National Defense Industry Press and Springer-Verlag GmbH, 2017.

Sun, H., Cao, Zhao, Z.D., Kang, X., 2018. A hybrid approach to cutting tool remaining useful life prediction based on Wiener process, IEEE Transactions on Reliability, 67(3), 1294-1303.

Sun, H., Liu, Y., Sakao, T., Wang, Z., Configuring use-oriented aero-engine overhaul service with multiobjective optimization for environmental sustainability, Journal of Cleaner Production, 2017, 162: S94 S106,

Sun, H., Zhang, X., Niu, W., 2016. In-process cutting tool remaining useful life evaluation based on operational reliability assessment. International Journal of Advanced Manufacturing Technology, 86(1-4), 841-851.

Wang, D., Tsui, K.L., 2018. Brownian motion with adaptive drift for remaining useful life prediction: revisited, Mechanical Systems \& Signal Processing, 99(1), 691-701.

Wang, P., Gao, R., 2015. Adaptive resampling-based particle filtering for tool life prediction, Journal of Manufacturing Systems, vol. 37, pp. 528-534.

Xu, W.G., Cao, L. 2015. Optimal tool replacement with product quality deterioration and random tool failure. International Journal of Production Research, 53(6), 1736-1745.

Yi, Q., Li, C., Tang, Y., \& Chen, X. 2015. Multi-objective parameter optimization of CNC machining for low carbon manufacturing. Journal of Cleaner Production, 95, 256-264.

Zaretalab, A., Haghighi, H. S., Mansour, S., Sajadieh, M. S. 2019 Optimisation of tool replacement time in the machining process based on tool condition monitoring using the stochastic approach, International Journal of Computer Integrated Manufacturing, 32(2), 159-173.

Zhang, Z., Si, X., Hu, C., Lei, Y., 2018. Degradation data analysis and remaining useful life estimation: a review on wiener-process-based methods, European Journal of Operational Research. DOI: 10.1016/j.ejor.2018.02.033.

Zhou, G., Lu, Q., Xiao, Z., Zhou, C., Yuan, S., \& Zhang, C. 2017. Ontology-based cutting tool configuration considering carbon emissions. International Journal of Precision Engineering \& Manufacturing, 18(11), 1641-1657.

Zhou Y, Xue W. 2018. Review of tool condition monitoring methods in milling processes. International Journal of Advanced Manufacturing Technology, 96(5-8), 2509-2523. 


\section{Highlights}

- An approach to enhance cutting tool sustainability is proposed.

- It extends a cutting tool's life based on its individual RUL prediction.

- It optimizes machining parameters to improve machining efficiency or capability.

- Cutting tool sustainability is assessed and its improvement is verified. 